\title{
The Effectiveness of Guidance and Counseling in Teaching Learning Process at Gomorefu High School in Mutare District
}

\author{
Chikwature, W. \\ Mutare Polytechnic, Research Department \\ P.O. Box 640, Mutare \\ whatmorec@gmail.com \\ Oyedele, V. \\ Africa University, P.O. Box 1320, Mutare \\ oyedelev@africau.edu
}

\begin{abstract}
This write-up is focusing on the effects of guidance and counseling into school, undertaking this curriculum procedure which we believed to have its own educational implications set from guidance and counseling objectives. Experimental research design was used and 40 form two pupils were the population. Introduction of guidance and counseling to twenty pupils was done who operated as a treatment group, the research was done throughout the year, pupils were to be given guidance and counseling with the aim of better educational aims, through test writing exercises. Questionnaires, interviews and observations were the main data collection tools. It was discovered that out of twenty pupils selected, three did no manage to do as per expectation and the other seventeen candidates managed to have positive results and had the ability of understanding and mastering the importance or guidance and counseling with relationship to educational subjects and society at large. Thus the results confirms the importance of the need to include guidance and counseling in the educational curriculum of the school.
\end{abstract}

Ke ywords : Effects, Guidance and Counseling, Secondary School, Curriculum

\section{INTRODUCTION}

Teaching any subject requires the teacher to find and use the most and effective method that combines all processes and equipment of teaching and this includes guidance and counseling. A provision of diversified courses of instruction imposes on teachers and school administrators the additional responsible of giving proper guidance to pupils in their choice of subjects and careers. The secrete of good education consists enabling the pupils to realize what are his/her talents and aptitudes and in what manner and to what extend he can best develop so as to achieve proper social adjustment and seek right types of friends so as to improve in learning activities. According to Baker and Gerler (2001), students who take part in school guidance and counseling program had significantly less in appropriate behavior and more positive attitude towards school than those students who did not participate in the program. Reviews of the research on schools are important to school climate and crucial elements in improving pupil's achievements, the review of the research on school counseling shows the services of school counselors have positive effects on school. Barker and Gerler (2001) emphasized that, group counseling provided by school counselors significantly decreased participant aggressive and hostile behavior and schooling guidance and counseling interventions have substantial impact of student's educational and personal developments. Missori (2000) on high school study shows that schools with more fully unimplemented mode/guidance and counseling programs had students who were more likely to report that:

- They had earned high grades

- Their educator was better preparing

- Then the future

- Schools made more career and college and information to available to them and that school had a more positive climate 
According to Westhood P (1992), guidance and counseling should be an integral part of education and it should be developmental, career oriented and multi-culturally appropriate in meeting all students need, while facilitating their academic success. In support of this Awaresome (1999) is in view that school counselors help to make learning a positive experience for every student. They are sensitive to individual differences. They know that classroom environment that is good for a child in not necessarily good for another. Counselors facilitate communication among leaders, administrators and students to adapt the schools environment in the best interest of each individual student. They help the individual student make the most of their school experiences and prepare them for the future. Also, educational guidance and counseling of students with disabilities is addressed with the facility education for all handicapped children and thus no segregation for opportunities will be realized among pupils owing to this guidance and counseling motivates both the handicapped and the pupil in the main stream. Since career guidance is the process of helping an individual select, prepare for, enter and function effectively in an occupation, the leader should guide and counsel those affected so that they can resolve their part of interest as well as exploring alternatives. Mainly guidance and counseling consists pupils to acquire such knowledge of characteristics, functions, duties and rewards of groups of occupation and also enables student to find out what general and specific abilities, skills are required for the group of occupation under consideration of age, preparation and sex for entering them. Jackson (2015) advocates for guidance and counseling in schools as it is adolescence that the children begin to think more seriously about their future careers and their attention. At this age his facts were based on the notion that schools are in a better position to collect comprehensive and reliable information concerning an individual, that is his/her health and scholastic records and general intelligent. The public has faith and confidence in schools and also feels that schools reside a genuine fair minded and honestly services. Makore-Rukuni (2013).in contrary asserts that Guidance and counseling impact knowledge and awareness of foreseen circumstances of the future that may not be rightful for a person so that one can be able to take rightful decision that may be good for him/her". In this he reviews the dissatisfaction of guidance and counseling as it shelters that idea of the counsel and not of the person being counseled. He advocates that guidance and counseling has a negative effect on students since student can become obsessive and student can neglect everything else, like their social life, family and friends. It denies pupils to follow their hearts pre leading that everything else said by the counselor is true and what they think / what they wish for does not exist. However, some pupils like guidance and counseling and some dislike it, for they have past experience of the past pupils or the previous pupils who ire guidance and counseled but ire failures in life and because of this guidance and counseling is denied to be an effective tool in administering pupil's for future achievement. A well planned guidance and counseling can provide assistance to individual boys and girls in deciding upon their future careers and education and other personal problems. Guidance and counseling is an instrument which should be used and encouraged by both teachers and school administrators to motivate learners. At Gomorefu High School, guidance and counseling is viewed as an activity designed for undisciplined pupils. Guidance and counseling can be recalled an activity that is systematically planned to meet the need of all students and are infused into daily activities of school. Comprehensive guidance and counseling programs and service support student learning in areas of personal, social, education and carrier development aspect of their disciplinary status. The researchers are in the view that even well disciplined students may be caught un-wanting, in the face selection of subjects and friends and thus through guidance and counseling the pupils be served. It is against this background that the researcher sought to investigate the effectiveness of including guidance and counseling on pupil's performance in the teaching curriculum of form two levels at Gomorefu High School.

\section{Research Questions}

1. How pupils are identified or selected for guidance and counseling

2. What attitudes are portrayed by teachers, a school head and pupils toward guidance and counseling?

3. How best can guidance and counseling be accommodation in school curriculum?

4. What strategies should be employed in guidance? 


\section{MATERIALS AND METHODS}

\subsection{Research Design}

Introduction of education research method model (E A 3 D C.10.) a research design is the grant plan for enhancing internal and external validity or a research study. This entails essentially the manner in which one should handle outside variables such that they do not interfere with the internal and external validity of research study. The researchers used the experimental research design. The descriptive survey used aims at giving a clear picture of the frequency and distribution of a given characteristics in an identical population. The researchers described the teacher and the pupils' attitude towards guidance and counseling. The researchers explore the relationship between guidance and counseling and pupils' performance in school work.

\subsection{Population Sample}

Guided population used in the research project comprises of forty (40) pupils at Gomorefu High School and pupils ire randomly selected irrespective of the ability on performance on school work. The researchers used some little cards labeled "YES" and "NO". The pupils had to pick the cards and those picked "YES" ire taken into the research program. The researchers observed pupil's performance in the first week and offered a guidance and counseling session for those who did less than expected and those who did extremely very ill. Of the selected pupils, the researchers studied the habits and attitudes towards learning and this used the results to carry out guidance and counseling so as to improve in academic excellence.

\subsection{Interviews}

An interview is a two person conversation initiated by the interviewer for the specific purpose of obtaining research -relevant information, and focus by him on the content specified by research objectives of systematic description, prediction or explanation (Cannel and Kahn, 2010 in Oyedele, 2011). There are several types of interviews which include personal and telephone interviews. For the purpose of this research personal interviews ire used and these ire semi-structured.

Gill and Johnson (2010) define a personal interview as a systematic way of gathering information through asking the same set of questions in a consistent manner to all selected respondents on a faceto-face basis. Interviews are particularly useful for getting a story behind a participant's experiences, beliefs and feelings. A personal interview is unique in that it involves the collection of data through direct verbal interaction between the interviewee and the interviewer (Ghosh, 2015). Through respondent's comments, facial and bodily expressions, evasiveness and cooperation or noncooperation, the interviewer acquires information that would not be conveyed through any other way. Therefore, personal interviews ire used on teachers, peer educators and humanitarian organisation so as to gain such important information.

Personal interviews ire useful in this research because there was some kind of information which was almost impossible to obtain through any other means. For example, information about teachers' attitudes on guidance and counseling programmes may be obtained more accurately by asking for verbal explanations or reports from the persons concerned. Moreover, where the intention is to study perceptions, feelings or related attitudes on guidance and counseling, then asking counselors to describe what they see, feel, and believe may be the only possible way to obtain such information. Interviews may also clear misconceptions and misunderstandings about a question and keep the respondent on the track of providing essential information.Clarifications and explanations may also be provided by the interviewer.

\subsection{Questionnaires}

A questionnaire is an instrument of measurement and data collection which is used to compile information from people (Oyedele, 2011).It involves the incorporation of peoples' views, opinion, perceptions, habits and behaviours on a certain topic, event or occasion. The questionnaire document usually asks many people the same questions to which the respondents record their answers either in written form or ticking in the boxes provided,(Oyedele, 2011).In this research, questionnaires ire distributed to teachers, in order to gain their views on guidance and counseling in secondary schools. Closed and open-ended questions ire used in the questionnaire form. 
The questionnaire has advantages. It is flexible and convenient instrument in that the respondent may answer the question at his/her own time, answer it in any way and may take a number of sittings to complete it. In this way, it gives the respondent ample time to think about the answers, make reflections and organize his/her thoughts and opinions,(Leedy, 2010). This might lead to the production of a ill thought out document with relevant answers to the questions. The respondent may also be given space to write his/her comments and feelings which might help the researchers to get insights into the opinions of the respondents. The instrument is also cheap to use over a large geographical area. Oyedele (2011) propounded that it is a cheap and quick instrument of collecting data. Therefore, if properly distributed, the questionnaire instrument may be used to minimize the costs of carrying out a research. The fact that respondents complete the questionnaire form on their own and at their convenient time gives them freedom of expression and reduces fears of being victimized. Leedy (2010) pointed out that the questionnaire technique gives the respondent time to respond freely without fear of victimization as anonymity is granted and confidentiality guaranteed.

\subsection{Observations}

One observation schedule was prepared and used for all the students and teachers under study. Observation is the term applied to methods of gathering data without direct questioning. It is the primary technique for collecting data on nonverbal or social behaviour, (Oyedele, 2011). Nonparticipative overt observation was the focus of the study. An observation check list was used to gather data. The findings of the observation ire also saved as a guide authenticating the responses in either the interviews or questionnaires. The researchers carried out a visit to each school for the observations. Observations ire conducted in between questionnaire completion and interviews. Researchers took that opportunity to probe into areas that ire not addressed satisfactorily in the questionnaires.

\section{RESULT AND DISCUSSION}

The research aimed at examining of the introduction if guidance and counseling could whether improve pupils performance in schools. Pupils performance was observed during the course of the first term in order to trace notify the lying factors in their learning processes. An improvement in performance was measured by a comparison on pupils' work which they performed between first term ascension test and midyear examination administered.

The need to have data presentation, analysis, interpretation and synthesis is necessary since the raw data does not reflect a comprehensive and detailed analysis of development, in fact, improvement in pupils' performance after given guidance and counseling.

Table 1 below gives the magnitude of improvement in the performance of the pupils.

Table1. Magnitudes of Improvement in Performance

\begin{tabular}{|l|l|l|l|}
\hline CODE & ASSESMENT \% & MID YEAR \% & MAGNITUDE OF FAIL/ RAISE IN \% \\
\hline A & 57 & 64 & 7 \\
\hline B & 54 & 61 & 7 \\
\hline C & 50 & 66 & 16 \\
\hline D & 55 & 50 & -5 \\
\hline E & 63 & 51 & -15 \\
\hline F & 51 & 59 & 8 \\
\hline G & 57 & 59 & 2 \\
\hline H & 50 & 52 & 2 \\
\hline I & 47 & 61 & 14 \\
\hline J & 29 & 44 & 15 \\
\hline K & 33 & 33 & 0 \\
\hline L & 29 & 46 & 17 \\
\hline M & 57 & 59 & 2 \\
\hline N & 63 & 58 & -5 \\
\hline O & 43 & 67 & 16 \\
\hline P & 59 & 58 & 8 \\
\hline Q & 42 & 50 & 18 \\
\hline R & 50 & 50 & 0 \\
\hline S & 48 & 62 & 14 \\
\hline T & 50 & 53 & 3 \\
\hline
\end{tabular}


The Effectiveness of Guidance and Counseling in Teaching Learning Process at Gomorefu High School in Mutare District

To some up with a valid interpretation and clue of pupils programme in their school performance, the scores are rearranged into their rank of use in performance. This is to be presented in table 2

Table2. Shows the Scores Obtained By Pupils in Order of Merit of Improvement

\begin{tabular}{|l|l|l|l|l|l|l|l|l|l|l|l|l|l|l|l|l|l|l|l|}
\hline & L & O & C & J & I & S & F & P & A & B & T & G & H & M & R & K & D & N & E \\
\hline $\begin{array}{l}\text { Assessment } \\
\text { Mark }\end{array}$ & & & & & & & & & & & & & & & & & & \\
\hline $\begin{array}{l}\text { Assessment } \\
\text { percentage }\end{array}$ & 29 & 43 & 50 & 29 & 47 & 48 & 51 & 59 & 57 & 54 & 50 & 57 & 50 & 57 & 50 & 33 & 55 & 63 & 63 \\
\hline $\begin{array}{l}\text { Midyear } \\
\text { examination }\end{array}$ & & & & & & & & & & & & & & & & & & & \\
\hline $\begin{array}{l}\text { Midyear } \\
\text { percentage }\end{array}$ & 46 & 59 & 66 & 44 & 61 & 62 & 59 & 67 & 64 & 61 & 53 & 59 & 52 & 59 & 50 & 33 & 50 & 58 & 51 \\
\hline $\begin{array}{l}\text { Magnitude of } \\
\text { rise/fall } \\
\text { in percentage }\end{array}$ & 17 & 16 & 16 & 15 & 14 & 14 & 8 & 8 & 7 & 7 & 3 & 2 & 2 & 2 & 0 & 0 & -5 & -5 & -12 \\
\hline
\end{tabular}

The rank order of rise or fall in performance reveals that out of the 20 pupils included in the guidance and counseling, 17 pupils performed well with a percentage of $85 \%$ of varied magnitude.

On the other hand out of 20 pupils 3 pupils performance actually fell, while some of the pupils' performance remained constant.

Performance in pupils varied by margin of either negative or positive because of many influential factors in determining the impact of guidance and counseling on pupils' performances. The reason being that there are differences in individuals on dealing with problems hence the following assumptions can be made and taken into consideration.

- No two learners achieve at the same rate/grade

- No learners solved problems in the exactly same way and the same capacity to learn

- No two learners passed the same pattern of interest.

- No two learners are maintained to achieve the same degree

- No two learners are ready to learn at the same time.

Gathering those assumptions with assumptions with variations in home, city and school environment the researcher infers that the learning of the study carried out with the aim to improve varied ways and magnitudes either positively or negatively.

Westwood (1992) says perhaps in reality small differences between individuals may not demand individualized instruction. Learning is a unique process hence the impact of guidance and counseling on pupils performance is bound to be different according to behaviors.

However no valid conclusion can be made without a further analysis and interpretation of data. The data is therefore presented in order to make an assessment of the frequency distribution of pupils scores of three categories noticed above.

Table3. Frequency distribution of change in performance

\begin{tabular}{|l|l|l|}
\hline Magnitude percentage interval & tally & frequency \\
\hline $16-20$ & 1111 & 4 \\
\hline-15 & 111 & 3 \\
\hline $6-10$ & 1111 & 4 \\
\hline $1-5$ & 1111 & 4 \\
\hline $0-(-4)$ & 11 & 2 \\
\hline$(-5)-(-10)$ & 11 & 2 \\
\hline$(-11)-(-15)$ & 1 & 1 \\
\hline
\end{tabular}

The data above is confirmed graphically by a histogram. 


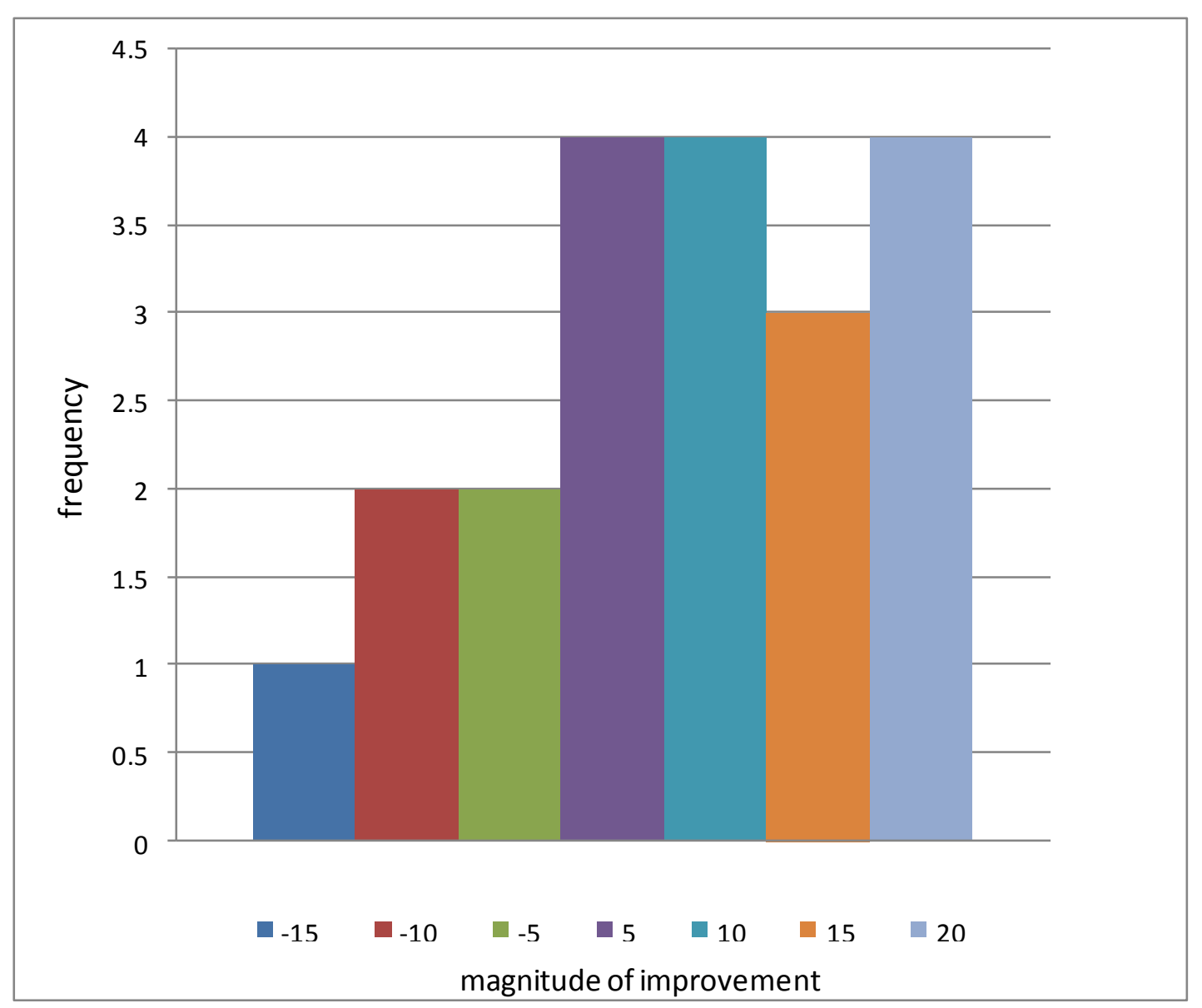

Figure1. Graphical presentations of distribution and change in pupils' performance

In general preview of the histogram shown in fig 1 above, indicates that pupils' performance improved, due to the effectiveness of guidance and counseling session on remediation and during lesson time. Also, Cordad (1988) supports that any child is capable of producing something fruitful if a well programmed learning of counseling is applied.

Table4. A comparison between assessment tests results and midyear examination results.

\begin{tabular}{|l|l|}
\hline & Average percentage \\
\hline Assessment test \% & $49.35 \%$ \\
\hline Midyear examination \% & $55.60 \%$ \\
\hline Combined \% & $52.5 \%$ \\
\hline
\end{tabular}

Before any conclusion can be made, the information can be deduced into mean (scores) of positive and negative percentage in order to show the impact of guidance and counseling on pupils performance.

Table5. The mean percentage rise/fall

\begin{tabular}{|l|l|l|l|}
\hline & Assessment \% & Midyear 5 & combined \\
\hline Performance mean & 49.4 & 55.6 & 52.5 \\
\hline
\end{tabular}

The table above reflects that mean performance of pupils had improved by 6.2 percent, and a combination of two mean marks gives $52.5 \%$ which also indicates a $3.1 \%$ rise. The improvement in the mean marks is attributed to the guidance and counseling exercise carried out after the assessment test which was before the midyear examination test.

\section{Percentage Improvement in Performance}

- Twenty pupils were involved in the study of guidance and counseling

- Out of the twenty pupils, seventeen pupils performance improved

- Out of the twenty pupils, three pupils performance was negative towards the aim of the research. 
The Effectiveness of Guidance and Counseling in Teaching Learning Process at Gomorefu High School in Mutare District

\subsubsection{Positive impact percentage}

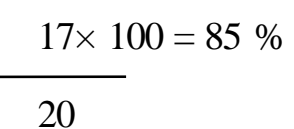

\subsection{2}

Negative impact percentage

$3 \times 100=15 \%$

20

These expressions above, can be expressed in a pie chart as below

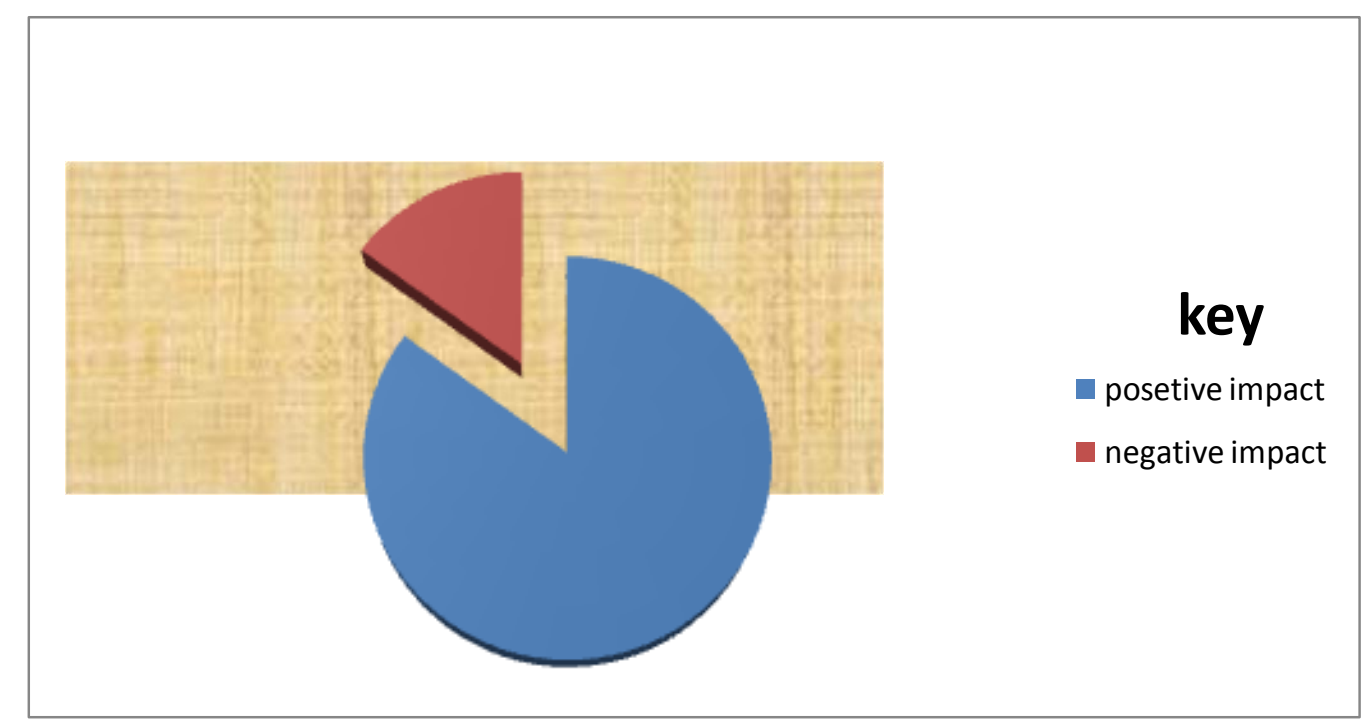

Figure2. Impact of Guidance and Counselling

The pie chart shows the impact of guidance and counseling on pupils performance. $85 \%$ of the pupils who were given guidance counseling session saw their improvements in their performance; however $15 \%$ of the pupils experienced a negative impact on their performance. The actual fall in the performance of this, $15 \%$ reveals that they are varied aspects that contribute to this impact. These aspects according to the researcher's point of investigation range from attitudes towards guidance and counseling, strategies lacking from sociological and psychological status/backgrounds.

Pupils' performance can further be translated into graph showing the pass rate

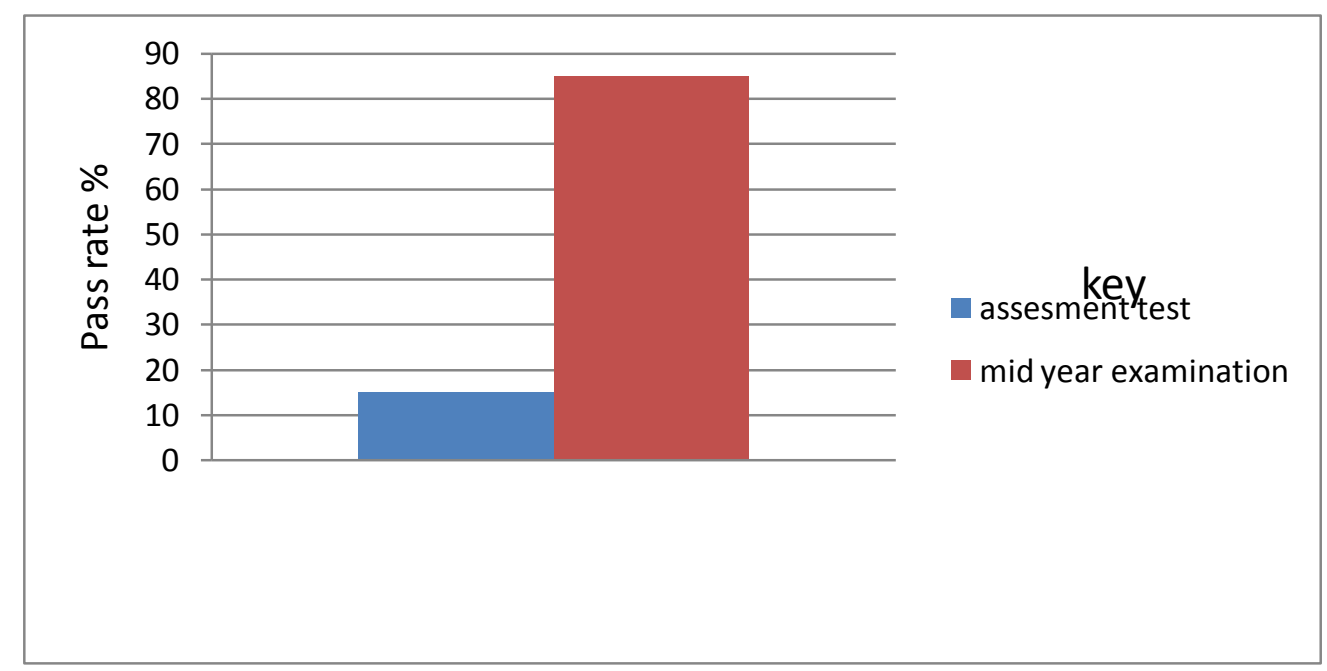

Figure3. Comparison of pass rate in pupils' performance. 
A closer survey of data reveals that the pass rate of pupils improved from $25 \%$ to $85 \%$. In other words before guidance and counseling, $15 \%$ failed to obtain $50 \%$ and above. Sampson (2004) further says guidance and counseling is richly rewarding to a committed teacher but makes greater demands on him.

\section{Conclusions}

The provision of the study narrated varied learning abilities. $85 \%$ of pupils' performance greatly improved and $15 \%$ of the pupils failed, the examiner/researcher observed that pupils need to be remediated but not in the same counseling and teaching way, same time, one same place. Strategies should vary in the sense that no pupil can solve the problem in the same way. Mainly in reality, small differences between individuals may not demand individualized instruction, hundred years of educational experience have repeatedly confirmed the fertility of looking for the one method which is used by teachers, will reach the pupils.

Pretest and post-test were used as the instruments for data collection presented. Results revealed that the inclusion of guidance and counseling is a very essential and productive for better academics and behavioral change performance.

The hypothesis had been compiled with test verification. It is apparent that guidance and couns eling necessitates better learning and retention of a better pupil trends

A comparison of pass rate of the pot-test results showed that the experimental group for which guidance and counseling was introduced at a new teaching variable had $85 \%$ pass rate. This grant the argument that guidance and counseling provide the best learning etiquette character with desirable results.

\section{RECOMMENDATIONS}

In the view of the research findings and outcomes, the investigator/researcher had the following recommendations to potential researchers on the project.

Prospective researchers' should be prepared to tolerate deviance tendencies and should not personalize them as this is part of learning and living together as to be open and acknowledge cooperative behavior.

- Guidance and counseling is an ideal essence in teaching and learning process of pupils a teacher should take cognisance of this and use it more often in the teaching and learning process in this dynamic and modern life.

- Both groups of pupils and researchers involved should be un-dependent of each other with no association between them, to make different findings authentic.

- Pupils can also carry out this guidance and counseling on their spare time provided they are given a guiding frame to work over a period of time especially on weekends so that they become observant and to be aware of activities.

- Whenever possible, the school authorities should explore methods of organizing learners than labeling/streaming them

\section{REFERENCES}

Awaresome (1999), Counselling in Schools, University of London

Barker S.B and Gerler E.R (2001), Elementary School, New York, USA

Cohen- Manion (2007) Guidance and Counselling Education Tool, London, Mc Raw Hill

Cordard (1998) Life of Guidance and Counselling in a Society, New York, USA

Ghosh, B.N. (2015).Scientific Methods and Social Research. New Delhi: Sterling Publitheyrs.

Gill, J.and Johnson. (2010).Research Methods for Managers. Boston: Paul Chapman

Jackson, H. (2015).Africa: Continent in Crisis. Harare: SAFAIDS

Leedy, P.D. (2010).Practical Research: Planning and Designing. New York: Macmillan Publishers. Makore-Rukuni, M.N. (2013).Counselling of Special Populations. Harare: University of Zimbabwe. Missori (2000), A Review of School Counselling, University of London 
The Effectiveness of Guidance and Counseling in Teaching Learning Process at Gomorefu High School in Mutare District

Oyedele, V. (2011) .Research Methods for Education Students. Windhoek: Zebra Publishing

Samson OC (2004) Guidance and Counselling for Tertiary Students, Oxford University Publishers

Westhood P (1992), A New Model for Researching the Science of Guidance and Couns elling, Oxford University Publisher

\section{AUTHORS' BIOGRAPHY}

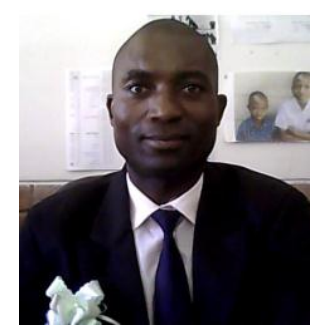

Chikwature Whatmore (Dr), He holds a $\mathrm{PhD}$ in Education, Master of Education in Educational Management, Bachelor of Arts in English and Communication Studies, Diploma in Secondary Education, and many other credentials and has started on his second $\mathrm{PhD}$ in Educational Administration. $\mathrm{He}$ is Research Methods and Statistics senior lecturer and Human Resource Development senior lecturer at Mutare Polytechnic. He is also a part time lecturer in Masters of Educational Leadership, and Management Programme at Africa University in these subjects: Research Methods and Statistics, Leadership, and Policy studies and Educational Administration. Published 19 research papers to date on Educational Leadership and Management issues.whatmorec@gmail.com

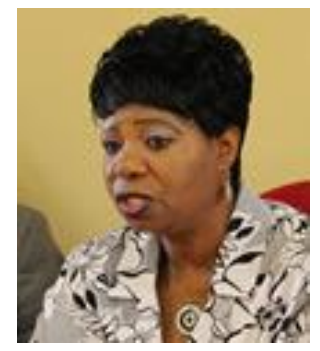

Oyedele Victoria (Dr), $\mathrm{PhD}$ and Master in Curriculum Studies, BSc. Ed (Biology). Senior lecturer and Dean of Students in the Faculty of Education at Africa University. Expert in Research Methods and Statistics, Curriculum Studies and Educational Evaluation. She has written over 20 research papers on educational leadership and administration. She has written some books also notably in Research Methods and Statistics and on Curriculum issues.

oyedelev@africau.edu 